\title{
MEMORIALES, MONUMENTOS, MUSEOS: MEMORIA, ARTE Y EDUCACIÓN EN LOS DERECHOS HUMANOS
}

\author{
Ricardo Brodsky Baudet \\ Museo de la Memoria y los Derechos Humanos - MMDH, Santiago - Chile. \\ <rbrodsky@museodelamemoria.cl>
}

http://dx.doi.org/10.1590/ 0102-6445149-161/96

Las preguntas que guían este artículo nos remiten al tema de la posibilidad o imposibilidad del arte de representar el horror y contribuir con esa representación a un consenso ético que prometa la no repetición de los hechos. Aunque hoy día hacemos en este coloquio hincapié en cómo los museos de la memoria contribuyen a la reflexión y educación sobre los derechos humanos actuales y refuerzan los valores democráticos, las preguntas señaladas no son nuevas. Todavía retumba la dialéctica y hasta contradictoria sentencia de Adorno: no es posible la poesía después de Auschwitz.

En efecto, como plantea Andreas Hyussen, conservando las distancias políticas e históricas, el discurso del holocausto pareciera proyectar su sombra sobre los debates de los desaparecidos y desaparecidas en América Latina. Y esto porque algunas de las preguntas que subyacen son las mismas: ¿Admite el trauma una representación artística? ¿Cuál es el papel que juegan las obras de arte en los procesos públicos que atraviesan una memoria nacional traumática? $¿$ Es posible que exista alguna vez consenso sobre un período 
que dividió y divide radicalmente al pueblo en vencedores, vencidos, beneficiarios y víctimas?

No se puede olvidar, como nos recuerda Regine Robin (2012) en su obra La memoria saturada, a este respecto el trabajo de Jochen Gerz quien entrevistó a más de setenta artistas, arquitectos, músicos y miembros de la Academia de Arte de Berlín, para que le dieran su punto de vista sobre los debates que rodeaban la construcción de un memorial en homenaje a los judíos asesinados por la Alemania nazi. Tras grabar y filmar cientos de horas se dio cuenta que los momentos más relevantes, los más auténticos, eran aquellos en que sus entrevistados se quedaban en silencio. Por eso terminó instalando un plano de 62 caras haciendo silencio.

\section{Las políticas de representación post dictatorial y la participación de los/las artistas}

El Museo de la Memoria y los Derechos Humanos (MMDH)

150 es un dispositivo cultural en el que, en un edificio de 5 mil metros cuadrados, la sociedad chilena cumple simbólicamente su deber de memoria, esto es, mira de frente su pasado y responde al derecho a la memoria de las víctimas de la dictadura.

$\mathrm{Su}$ origen se encuentra en las recomendaciones del Informe de la Comisión Nacional de Verdad y Reconciliación de 1991 y en la declaración por parte de Unesco de los archivos de diversos organismos de defensa de los derechos humanos de Chile, como Memoria del Mundo, en 2003. A ello se agregó la demanda de las propias organizaciones de familiares y víctimas de las violaciones a los derechos humanos. En el Museo se concentra y preserva la mayor colección de documentos, fotografías, objetos, testimonios y películas sobre el período dictatorial existente en el país, se la exhibe al público buscando producir la empatía con las víctimas y el rescate de valores y lecciones de la experiencia de atropellos a los derechos humanos. 
Las agrupaciones de víctimas que originalmente fueron distantes del proyecto de instalación del Museo de la Memoria, por cuanto veían en él un proyecto de carácter estatal que de alguna manera usurpaba su memoria, hoy participan activamente de su vida y se sienten mayoritariamente incorporados y reconocidos.

El MMDH se construye luego de un concurso internacional de arquitectura, en un espacio neutral de la ciudad de Santiago, sin la carga de un "sitio de memoria", pero con una capacidad de evocar por momentos toda la carga simbólica de un memorial. Se premió la solución presentada por una oficina brasileña llamada Estudio América que integran los arquitectos Carlos Dias - quien lamentablemente falleció este año (2014) -, Lucas Fehr y Mario Figueroa, a la cual se asoció el chileno Roberto Ibieta.

Al presentar el proyecto, sus autores sostuvieron que "las memorias son figuras que viven en un mundo inconcluso, fragmentos de hechos irrepetibles que no se sucederán dos veces”. Entendemos como memoria no un deseo de volver hacia atrás, de sustituir lo insustituible. "Para nosotros la memoria no es arrepentimiento. Es mirar el futuro sabiendo del pasado" (Figueroa, Fehr y Dias, 2010, p. 35).

Conforme a lo anterior, la arquitectura del museo traduce el desafío de construir un edificio que refleja cómo nuestra sociedad se hace cargo del tema de las violaciones de los derechos humanos durante la dictadura, fortaleciendo la valoración de la tolerancia y la democracia y el respeto irrestricto a la dignidad de las personas.

Se trata de un museo de la memoria en un país singular entre la cordillera y el mar. Un museo que desea ocupar esta franja reverenciando a través de una mirada simbólica estos dos elementos determinantes de la geografía chilena marcados en el alma del pueblo. La memoria evidenciada, emergente, flotante, suavemente elevada. Un arca donde se pueden depositar todas las reminiscencias 
de una parte invisibilizada de la historia chilena. Un espacio dedicado a la memoria puede no solamente transmitir informaciones, sino también provocar la reflexión sobre los recuerdos y deseos.

El MMDH como espacio de tributo especialmente a las víctimas: detenidos desaparecidos, ejecutados políticos, presos políticos, relegados, exiliados, torturados y familiares, en el que convergen relatos, imágenes, temporalidades, significaciones y experiencias diversas. Un lugar que detenta una función rememorativa donde la figura de la víctima ocupa un lugar trascendental. Lugar político en consecuencia, pero espacio de educación y de arte a la vez.

En efecto, el MMDH no agota su función en la formación de una colección a la que el público puede acceder y en la exposición de las huellas materiales del pasado dictatorial, a través de su exposición permanente, sino que abre las posibilidades de lectura de la historia a una dimensión

152 subjetiva, poética y complementaria al relato objetual. Es este doble carácter el que permite definirlo como una construcción discursiva compleja en la que convergen políticas y estéticas de la memoria.

Los conceptos generales tras una selección bastante precisa de estrategias de representación de la memoria del Museo, son el trauma, la identidad, la huella, el testigo, el memorial, la ausencia, la identidad, la resistencia, situados bajo definidos ejemplos y formas precisas de representación visual de la memoria. Entendemos que la memoria ha adquirido una relevancia fundamental en la actualidad para el profundo conocimiento tanto del mundo como del individuo, y el arte se ha convertido en uno de los medios más importantes para llevar a cabo aquel trabajo de memoria.

Todos los museos que tratan con historias traumáticas conocen la tensión entre historia y memoria, entre el relato explicativo de los hechos cronológicamente organizados y la experiencia subjetiva del recuerdo que se afirma en el tes- 
timonio. Conjugar esa tensión es justamente el gran desafío de los museos de la memoria para que los testimonios expuestos se conviertan en ejemplares y representativos, trascendiendo el marco de la mera experiencia personal o de los grupos directamente afectados. Sólo resolviendo positivamente esa tensión logra hacer universal su mensaje y vincular las demandas de verdad y justicia con un imaginario democrático más amplio.

Según Maira Mora (2012, p. 70), la museografía del MMDH coincide con lo que Pierre Nora llama la transformación de la memoria en historia, esto es, "se apoya por completo en lo más preciso de la huella, lo más natural del vestigio, lo más concreto de la grabación, lo más visible de la imagen...”. En efecto, los visitantes se enfrentan a las huellas del pasado, los rostros de los desaparecidos, el bombardeo de La Moneda, los testimonios de los torturados, la angustia de los familiares, la protesta social, la reorganización política, es decir, se ven forzados a vivir una experiencia de aprehensión, de compasión, de empatía y de emoción. Pero también se encuentran con los documentos, los archivos legales, los bandos y decretos que llevan a una experiencia de confrontación, de análisis, de comparación, de visualización del contexto en que se desarrolló la violencia. En el Museo de la Memoria, el documento se transforma en un testimonio de verdad.

El Museo asume que lo que es controvertido en la sociedad lo debe ser también en el Museo. Por ello, nuestro esfuerzo pedagógico busca no abrumar a las audiencias con el horror sino permitirles una reflexión propia sobre los hechos presentados, descartando toda manipulación y asociaciones impropias o abusivas del pasado con el presente.

$\mathrm{Al}$ igual que tratamos a la memoria en forma multidisciplinar, las aproximaciones a las estrategias de representación de la memoria desde el arte también hay que mirarlas desde diversas perspectivas para lograr un acercamiento 
adecuado. Por eso, el MMDH contiene en la explanada, como parte de muestra permanente, la obra Geometría de la conciencia del artista Alfredo Jaar.

En una reciente entrevista, el curador paraguayo Ticio Escobar (2014), citando a Didi-Huberman, dice que aunque para algunos el horror impone un silencio extremo, constituye un deber ético convocar imágenes que puedan, aunque sea de manera parcial e intermitente, denunciar situaciones intolerables. Afirma que

Las imágenes no muestran todo: descubren y encubren siempre. Evocan, sugieren o predicen momentos que no pueden ser definitivamente aclarados: sus centelleos permiten divisar bultos inciertos, momentos de un todo sustraído; permiten percibir puntadas de verdad.

\section{Algunos ejemplos}

154 Geometría de la conciencia, obra de Alfredo Jaar, logra dar una respuesta inteligente y sensible a esta inquietud. Situada en la Plaza de la Memoria, Geometría de la conciencia es una obra subterránea. Por su materialidad, la obra impide una aproximación distraída de parte del espectador, obligándolo, literalmente, a sumergirse en ella. Ubicada 6 metros bajo tierra, se accede a un hall que no deja anticipar nada de la experiencia que otorgará el memorial. Se trata de un espacio cúbico aparentemente vacío, en el que el visitante es confrontado a experimentar la oscuridad total durante sesenta segundos.

La ausencia de luz y el silencio que reinan en el lugar, unidos al encierro que implica la obra, generan inevitablemente ansiedad y angustia en el espectador. Poco a poco, una luz tenue comienza a emanar de la pared frontal, dejando ver 500 siluetas que se recortan sobre un fondo negro. Evocan las siluetas que los familiares de los detenidos desaparecidos llevan en su pecho. La luz que proviene 
del interior de las siluetas se intensifica progresivamente, y el efecto de su aparición inesperada se incrementa por su multiplicación al infinito producida por dos espejos instalados en los muros laterales. De este modo, la obra rodea al espectador, y, como señala Adriana Valdés (2010, p. 46), la multiplicación al infinito de las siluetas crea una sensación ligada a la inmensidad inconmensurable de la pérdida. Tras alcanzar su máximo resplandor, la luz desaparece de improviso, sumergiendo una vez más al espectador en la oscuridad total por otros sesenta segundos.

Esta vez, sin embargo, subsiste la imagen retiniana de las siluetas, la que acompañará al visitante incluso una vez concluida la experiencia de la obra. Las siluetas que conforman Geometría de la conciencia provienen de dos fuentes: algunas de ellas fueron extraídas de fotografías de víctimas de la dictadura proporcionadas por las agrupaciones de familiares de detenidos desaparecidos; el resto fueron realizadas a partir de retratos tomados por el artista a ciudadanos chilenos contemporáneos. Según ha explicado el mismo Jaar, la composición mixta de la obra tenía por objeto romper el modelo tradicional de los memoriales, los que ocupándose sólo de las víctimas oficiales de la dictadura crean, según su parecer, una marginación de las mismas. Su obra, sin embargo, propone un ejercicio inverso.

La reiteración de imágenes que vemos en Jaar, pero también en el Memorial del Museo, en El siluetazo argentino, en las más recientes denuncias sobre lo ocurrido en Ayotzinapa, México, ha sido probablemente la técnica o la metáfora más difundida para manifestarse, denunciar o acusar las graves injusticias que ha conocido nuestra región. Otro ejemplo de ello es la obra Huellas, instalación de Kaarina Kaikkonen, bajo la curaduría de Julia Herzberg, en el MMDH en 2013. Huellas presenta una imagen simbólica de la vida cotidiana valiéndose de las prendas de ropa masculina y femenina. La prenda masculina en esta exposición 
representa la ausencia, la sensación de irremediable pérdida que tiene la autora con la muerte de su padre. Nos pone de este modo ante una entrada subjetiva que informa la construcción de la obra. Kaikkonen brinda una compresión formal y conceptual de cómo las variables del tiempo, el espacio, la materia y el contexto se unen mediante prendas de vestir, mediante chaquetas de hombre que pueden no estar, que desaparecieron, que son anónimos, prendas que relatan vidas.

Más de 850 chaquetas de hombre unidas entre sí y ubicadas sobre las gradas de una de las dos escalinatas del Museo. Las chaquetas están con sus frentes hacia abajo en los peldaños en rigurosa repetición. Sólo se observan dos excepciones: una chaqueta azul y una camisa blanca que están con sus frentes hacia arriba. Destacan, miran al cielo como una plegaria: son las prendas donadas por las madres de dos detenidos desaparecidos que esperaron más de trein156 ta años un lugar para depositarlas. La composición en su conjunto es dramática, las chaquetas están calladas pero no mudas, cada una tiene su historia. Instaladas en el Museo de la Memoria y los Derechos Humanos evocan, como la autora, la perdida, el olvido, el anonimato, la persistencia, la supervivencia y la memoria.

En otra clave, está la obra Lonquén, de Gonzalo Díaz, artista chileno premio nacional de arte. Trabajo expuesto en el MMDH en 2012. La obra de Gonzalo Díaz recuerda el hallazgo de los primeros cuerpos que evidenciaron que los detenidos desaparecidos eran una realidad, una práctica de las dictaduras del Cono Sur.

Arte y derechos humanos se unen aquí en forma natural. Personas sin militancia conocida habían sido desaparecidas como una venganza de terratenientes y fuerzas policiales dentro de un violento contexto de contra-reforma agraria. Según el autor, es imposible articular cualquier tipo de obra sobre los hechos, sino hasta bien pasados los años, por lo terribles y 
abrumadores. Dos piezas componen la instalación: un andamio de madera de cuartones de construcción presionado contra un muro con 2 toneladas de bolones de piedra de río, todas numeradas; y dos muros contiguos con 14 cuadros con marco de madera lacada negra. Lámparas de bronce iluminan cada cuadro como en la antigua pintura chilena. En los vidrios de cada cuadro impreso en serigrafía la frase: "En esta casa, el 12 de enero de 1989, le fue revelado a Gonzalo Díaz, el secreto de los sueños" (frase tomada de Freud). Cada cuadro enumerado con números romanos como postas del vía crucis; todo instalado para proponer en una no-figuralidad y en una no-imagen. La obra no representa los hechos de Lonquén en un plano ilustrativo de lo real. La obra propone la construcción de un imaginario paralelo, elementos que acentúan la distancia entre lo que fue el hecho y lo que es la obra. El asunto de la imagen (o la no-imagen) en un museo de la memoria dedicado a dar visibilidad a las violaciones de los derechos humanos es central. Lo artístico de Lonquén se encuentra en la imagen que construye y no en la figura a la cual se refiere.

$\boldsymbol{A D N}$, de Máximo Corvalán, artista chileno. Trabajo expuesto en el MMDH en 2012. ADN se compone de tres elementos: el agua, la electricidad reflejada en la luz y los huesos. Es parte de una obra mayor, en constante movimiento, que cruza los conceptos de precariedad y espectáculo. La investigación sobre el $\mathrm{ADN}$ tiene que ver con la identificación de los detenidos desaparecidos en un sentido amplio y renovado, hay más restos humanos que identificar. Los fragmentos de huesos representan la herida que no cicatriza, los vestigios brutales de la represión, unidos a la belleza visual de una serie de objetos lumínicos suspendidos sobre el agua, lo que pone al espectador en un punto de quiebre emocional. El agua y los huesos tienen un valor simbólico, generan un diálogo entre lo orgánico y lo abstracto. Es finalmente una reflexión sobre los cambios que 
está generando en la sociedad actual, con sus vibraciones y perturbaciones, el estudio del ADN.

Sustenazo (Lament II), video instalación de Mónica Weiss, bajo la curaduría con Julia Herzberg, expuesta en el MMDH en 2012-13. La historia se compone de historias paralelas, sostiene Mónika Weiss, múltiples historias convergen y ocasionalmente se superponen. Concibe su trabajo como poético y político: escuchar y abordar el archivo de los acontecimientos, prestando especial atención a las narraciones y las voces olvidadas. Sustenazo se desarrolló en torno a la noción de lamento como una forma de expresión ajena al lenguaje. La expresión atemporal del lamento se yuxtapone al archivo de un acontecimiento histórico específico: la repentina evacuación forzada del Hospital Ujazdowsky en el sexto día del Levantamiento de Varsovia. De niña le enseñaron en la escuela que ese acontecimiento nunca había existido, estaba prohibido hablar 158 del levantamiento en público. La obra de Weiss considera aspectos de la memoria y la amnesia pública ubicados territorial y espacialmente. ¿En qué lugar de la topografía y la conciencia de una ciudad podemos ubicar la memoria?, en el cuerpo, dice Weiss. En Sustenazo presenta en forma simultánea y superpuestos primeros planos del pecho de una mujer cubierto de dibujos quirúrgicos, de un mapa alemán de 1942 y de su propia mano enguantada. El cuerpo de la mujer representa en estos videos un cuerpo anónimo, una membrana entre el yo y el mundo externo. En Sustenazo, los gestos de lamentación o duelo son a la vez teatrales y mínimos; el lamento, performativo y comunitario, se convierte en una experiencia emocional compartida. No tiene que ver sólo con la historia de Polonia, se trata más ampliamente de la pérdida de vidas causada por la guerra y por otros actos políticos de violencia y opresión: la guerra no es sólo devastadora, es inaceptable. La obra de Weiss se ve reforzada por la música y el silencio, aunque 
no haya espacio con ausencia de sonido, ambos permiten que la obra respire.

Luis Camnitzer, Contra el Olvido, proyecto conjunto con el Museo de Arte Contemporáneo (MAC), expuesto en 2013. Otro artista que ha expuesto en el Museo de la Memoria. Para Camnitzer, el arte es sobre todo un instrumento de expansión del conocimiento. Explora preguntas sobre las funciones sociales del arte y la relación entre el artista y el espectador, donde el trabajo artístico es ante todo un instrumento de comunicación. En Contra el Olvido, Camnitzer reunió diversas obras como la serie "De la tortura uruguaya", de 1983, a la reescritura de la guía telefónica de Montevideo con los nombres de los detenidos desaparecidos en el año 2009 a las que unió intervenciones al interior y exterior del Museo con la frase "Fosa Común" y la ya conocida "El Museo es una escuela". Camnitzer busca con su arte perturbar a la política. No informarnos sobre la política sino afectarla. A su juicio, al entregar procesos más que resultados, el visitante al Museo se convierte en productor de la obra, en vez de mero espectador. Con ello nos da una lúcida y sugerente respuesta a algunas de las preguntas que nos hemos formulado en este artículo para impedir el enclaustramiento de la memoria de la violencia y las violaciones de los derechos humanos.

\section{Algo de los chilenos no pudieron ver}

Otra línea de trabajo nuestra ha sido una suerte de arqueología que busca recuperar exposiciones o manifestaciones artísticas que por distintas razones los chilenos no pudimos conocer en su momento de realización.

Artists for Democracy, el archivo de Cecilia Vicuña, curaduría de Paulina Varas, expuesto en el MMDH en 2014. La exposición recupera la memoria de un momento trascendente en la vida de la artista y en su compromiso con los derechos humanos y la democracia. En efecto, en 1974 Cecilia 
Vicuña co-fundó la agrupación Artists for Democracy en la ciudad de Londres y desarrolló una enorme movilización de artistas y una acción de arte colectiva que desembocó en el Royal College of Art de Londres ese mismo año con obras de John Dugger, Mike Leggett, Liliane Lijn, Roberto Matta, Julio Cortázar y la propia Cecilia Vicuña, entre otras destacadas personalidades del mundo cultural.

El archivo de Cecilia Vicuña, por otra parte, apela a una reflexión sobre los materiales, el valor simbólico y lo efímero de los instrumentos. La idea de la exposición es indagar otras posibles maneras de exhibir un archivo de artista a partir de una historia que late en nuestra memoria y sigue enunciando preguntas actuales: ¿Cuál es el papel del arte en los procesos democráticos? ¿Es necesario, y si lo fuera, dónde es posible hoy articular la práctica artística con la política contingente? ¿Cómo comprender la relación de arte, política y derechos humanos, en donde el arte mani160 fiesta esa capacidad única de nombrar lo indecible?

Esta exposición buscó recuperar este acto de solidaridad de los artistas europeos con el pueblo chileno que estuvo borrado de nuestra memoria por demasiado tiempo, al igual que lo está la Bienal de Venecia de 1974, dedicada en gran parte a marcar la solidaridad con el pueblo chileno y el rechazo a la dictadura y cuyo archivo esperamos exponer en 2016.

Por la Vida Siempre, la exposición inconclusa de la Universidad Técnica del Estado, es un trabajo curado por el artista chileno Mario Navarro, quien incentivó a los creadores de una exposición gráfica que debía inaugurar Salvador Allende el 11 de septiembre de 1973, para reconstruirla en el Museo de la Memoria y volver a exponerla, casi cuarenta años después. Los letreros son decididamente políticos: una denuncia acerca de la amenaza fascista que se cernía sobre el país y un llamado a evitar una guerra civil, en una gráfica decididamente rupturista con la dominante en la izquierda 
de la época. El Museo Guggenheim, en el contexto de su exposición Arte Latinoamericano Hoy, en 2014, reprodujo estos afiches en un hermoso formato de postales.

\section{Ricardo Brodsky Baudet}

es director do Museo de la Memoria y los Derechos Humanos (MMDH), de Santiago de Chile.

\section{Bibliografía}

ESCOBAR, T. 2014. Entrevista disponível em: <http:/ /www.artishock.

cl/2014/04/22/sobre-limites-y-posibilidades-entrevista-a-ticioescobar $/>$.

FIGUEROA, M.; FEHR, L.; DIAS, C. 2010. "El concepto". In: MUSEO de la memoria y los derechos humanos. Catálogo. Santiago.

MEMORIA del mundo. 2003. Disponível em: <http:/ /www.unesco.org/ new/es/communication-and-information/flagship-project-activities/ memory-of-the-world/register/full-list-of-registered-heritage/ registered-heritage-page-4/human-rights-archive-of-chile/ $>$.

MORA, M. 2012. "Museo de la Memoria y los Derechos Humanos: una apuesta estético-política de legibilidade de la experiência dictatorial”. Revista Cátedra de Artes, n. 11, Facultad de Artes, Pontificia Universidad Católica de Chile. Disponível em: <http:/ / catedradeartes.uc.cl/pdf/ catedra\%2011/4.-\%20Maira\%20Mora.pdf>.

ROBIN, R. 2012. La memoria saturada. Buenos Aire:s Waldhuter editores. VALDÉS, A. 2010. "Alfredo Jaar, la geometría de la conciencia”. In: MUSEO de la memoria y los derechos humanos. Catálogo. Santiago. 


\section{MEMORIALES, MONUMENTOS, MUSEOS: MEMORIA, ARTE Y EDUCACIÓN EN LOS DERECHOS HUMANOS}

\section{RICARDO BRODSKY BAUDET}

Resumen: El texto se refiere a la posibilidad o imposibilidad del arte de representar situaciones extremas relacionadas con la violencia o las violaciones de los derechos humanos, y la manera en que el Museo de la Memoria y los Derechos Humanos en Chile, ha trabajado estos conceptos desde el arte contemporáneo.

Palabras clave: Memoria; Arte; Derechos Humanos; Museo.

\section{MEMORIALS, MONUMENTS, MUSEUMS: MEMORY, ART AND HUMAN RIGHTS EDUCATION}

Abstract: The text refers to the possibility of art to represent extreme situations related to violence and violations of human rights and the way that the Museum of Memory and Human Rights in Chile has worked these concepts from contemporary art.

Keywords: Memory; Art; Human Rights; Museum.

Recebido: 25/06/2015 Aprovado: 02/08/2015 